\title{
A abordagem da sexualidade como aspecto essencial da atenção integral de pessoas com transtornos mentais
}

\author{
The inclusion of sexuality as an essential aspect \\ of comprehensive care for individuals with mental disorders
}

Jaqueline Almeida Guimaraes Barbosa ${ }^{1}$

Marina Celly Martins Ribeiro Souza ${ }^{1}$

Maria Imaculada de Fátima Freitas ${ }^{2}$

${ }^{1}$ Curso de Enfermagem, Centro Universitário Metodista Izabela Hendrix. R. Bahia 2020, Lourdes. 30112-011 Belo Horizonte MG Brasil. jaqueline@task. com.br

${ }^{2}$ Departamento de Enfermagem MaternoInfantil e Saúde Pública, Escola de Enfermagem, Universidade Federal de Minas Gerais.

\begin{abstract}
The scope of this study was to understand the representations of mental health service patients and professionals concerning the sexuality of the former. Thirty-nine patients and 54 professionals of the public mental health services, divided up into six focal groups, were interviewed individually. Data analysis was based on the Structural Analysis of Narrative technique. Individuals with mental disorders do not perceive sexual health as a right and have difficulty taking care of themselves in the face of gender stereotypes, and for the contexts related with exclusion and poverty. Among the mental health service professionals, sexuality negation of mentally-ill individuals had been the commom representation. They classify this behavior as "not a normal representation" and believe that it must be restrained. Dialogues about sexuality with users are almost inexistent. Mental health service professionals are not prepared for integral assistance, which requires permanent qualification and the inclusion of this subject in the fundamental formation of health related careers, in a interdisciplinary way.
\end{abstract}

Key words Sexuality, Mentally ill individuals, Sexually transmitted diseases, Nursing
Resumo O estudo teve o objetivo de compreender as representações de usuários e de profissionais de serviços de saúde mental acerca da sexualidade dos primeiros. Entrevistaram-se individualmente 39 usuários e 54 profissionais de serviços públicos de saúde mental por meio de seis grupos focais. A análise dos dados fundamentou-se na Análise Estrutural de Narração. Pessoas com transtornos mentais (PTM) não representam saúde sexual como direito e encontram dificuldades para se cuidarem em face de estereótipos de gênero $e$ pelo contexto de exclusão e pobreza. Entre os profissionais, as representações foram de negação da sexualidade das PTM, entendendo-a como "fora do normal" e que deve ser reprimida. Diálogos sobre sexualidade com os usuários são quase inexistentes. Os profissionais não estão preparados para assistência integral, o que requer capacitação permanente nos serviços e inclusão do tema na formação básica nas carreiras da área da saúde, de forma interdisciplinar.

Palavras-chave Sexualidade, Pessoas mentalmente doentes, Doenças sexualmente transmissiveis, Enfermagem 


\section{Introdução}

No eixo epidemiológico do Projeto PESSOAS, estudo recente multicêntrico nacional, realizado com mais de duas mil pessoas, acompanhadas em instituições públicas de atenção em saúde mental no Brasil, evidenciou que pessoas com transtornos mentais apresentam altas taxas de infecções sexualmente transmissíveis, sendo que as taxas pelo HIV foram superiores aos da população em geral ${ }^{1}$. Além disso, identificou-se que essa população tem vida sexual ativa, bem como comportamentos sexuais de risco ${ }^{2}$.

O estudo ainda apontou que oito por cento dos pesquisados fazem uso de preservativo em todas as relações, e $40 \%$ nunca o utilizaram. Além disso, 30\% assumiram ter relações sexuais em troca de dinheiro ou drogas, e $18 \%$ afirmaram ter sofrido algum tipo de violência sexual. Dentre as instituições pesquisadas, $61,5 \%$ tinham pacientes sabidamente infectados pelo HIV, mas apenas uma minoria dispunha de ações de promoção da saúde sexual e disponibilizava preservativos ${ }^{1,2}$.

Os dados apresentados evidenciam uma problemática a ser enfrentada pelos profissionais de saúde, bem como a necessidade de se avançar no conhecimento para a prestação de uma assistência integral que considere a sexualidade e a saúde sexual também para este grupo populacional.

Para lidar com essa situação, pressupõe-se que é preciso considerar as dificuldades encontradas pelos profissionais de saúde para a abordagem de aspectos relacionados à sexualidade de pessoas com transtornos mentais, tendo em vista ser esta uma temática considerada tabu social. Estudos mostram que pessoas com transtornos mentais são vistas como assexuadas ou com uma sexualidade que deva ser reprimida, o que se acredita ser um aspecto dificultador das ações de promoção da saúde sexual junto a esse grupo ${ }^{3}$.

Faz-se necessário, também, conhecer os aspectos subjetivos envolvidos nas ações dos sujeitos no que tange à vivência da sexualidade e do autocuidado para a saúde sexual ${ }^{4}$, sendo esse aspecto pouco considerado nas abordagens preventivas. As ações, realizadas na atualidade, caracterizam-se por serem generalizantes e repressoras e por considerarem as atitudes como fruto apenas de uma decisão racional. A literatura disponível aponta limitações dessas ações educativas, que não contemplam a pluralidade de significados que englobam a vivência da sexualidade e do autocuidado dos diferentes grupos sociais, não os afetando de maneira semelhante e eficaz, o que sinaliza a necessidade de avanços nesse campo ${ }^{5,6}$.
Paralelamente, os aspectos psicossociais, relativos ao autocuidado para a saúde sexual, são pouco investidos pelos profissionais de saúde no que diz respeito a este grupo populacional, sendo insuficientemente conhecidos. Os estudos existentes mostram que as mulheres encontram dificuldades para se autocuidarem por terem a vivência sexual regida por estereótipos de gênero, e que os homens expõem-se a situações de risco também por fatores ligados a crenças culturais masculinas ${ }^{7}$. Pessoas com transtornos mentais caracterizam-se por ser um grupo que já sofre com a exclusão social e com o preconceito, o que aponta maiores dificuldades para seu autocuidado.

Este estudo teve como objetivo compreender representações de profissionais de saúde acerca da sexualidade de pessoas com transtornos mentais e representações de pessoas com transtornos mentais sobre saúde sexual, considerando seus contextos de vida. Visa-se, por conseguinte, contribuir com dados que promovam a reflexão e a construção de novas estratégias de atenção à saúde sexual, na perspectiva da integralidade da assistência.

Estudos que considerem aspectos psicossociais, como os das representações sociais, têm fornecido contribuições significativas para o combate da vulnerabilidade face às Doenças Sexualmente Transmissíveis (DST) e HIV/Aids, considerando que as pessoas orientam suas condutas a partir de seu repertório de crenças, valores e atitudes, dentre os quais aqueles sobre sexualidade ${ }^{8}$.

\section{Métodos}

Trata-se de pesquisa de cunho qualitativo, que tem sua fundamentação na Teoria das Representações Sociais, considerada fundamental na análise de aspectos sociopsicoculturais que permeiam o processo saúde-doença e suas práticas sociais9. Adota-se aqui o termo 'representações', uma vez que toda representação é social ${ }^{10}$, e é construída na interação entre as pessoas e suas práticas sociais.

Entrevistaram-se, por meio de grupos focais, 54 profissionais que atuam em diversos serviços de saúde mental que compõem a rede pública do estado de Minas Gerais, provenientes das $28 \mathrm{Ge}$ rências Regionais de Saúde (GRS), dos Centros de Atenção Psicossocial (CAPS) I, II, III e CAPS $\mathrm{AD}$ (Centro de Atenção Psicossocial de referência para usuários de Álcool e outras Drogas), além de Centros de Convivência, selecionados por meio 
de sorteio, após definição das regiões de saúde do estado, e a concordância de participação pelas gerências dos serviços.

Os profissionais, participantes desta pesquisa, são de diversas formações acadêmicas de nível médio e superior; são enfermeiros, assistentes sociais, médicos, psicólogos, técnicos em enfermagem, dentre outros. Dentre os 54 participantes, sete eram do sexo masculino e os outros 47 do sexo feminino; a maioria, 32 deles, com idade entre 31 e 50 anos, e a maior parte foi composta por profissionais de nível superior, sobretudo com formação em Enfermagem (15 participantes) e Psicologia (23 participantes). Além disso, verificou-se que dentre os participantes, a maior parte possuía experiência de atuação nos serviços de saúde mental por um período de dois a dez anos. Quanto à função que exercem nos serviços, 28 desempenhavam cargos de coordenadores e administradores e os outros 26 eram profissionais diretamente envolvidos no cuidado em saúde.

Os debates foram gravados em áudio, com a seguinte questão norteadora: "Falem sobre o que pensam da sexualidade das pessoas com transtornos mentais". Questões de relance foram acrescentadas para se manter a entrevista em torno do tema central.

Nesta etapa do estudo com os profissionais que atuam nos serviços de saúde mental, buscou-se conhecer o discurso coletivo, considerando-se que é dentro do grupo, da coletividade, que surgem os conflitos e nos permite, com mais facilidade, revelar uma variedade de opiniões e representações sobre um determinado tema em questão. Ademais, é durante os grupos focais que emergem representações sob diferentes perspectivas, permitindo criar uma discussão. Desta maneira, permite que os participantes discutam a partir dos comentários ou ideias de outros. No grupo focal, diversos tópicos relevantes, que numa entrevista individual pode não emergir, podem surgir durante a discussão.

Para a coleta de dados junto às pessoas com transtornos mentais severos e persistentes, utilizou-se a entrevista aberta, solicitando-as contar sobre seu contexto de vida inclusive a sexual, com inclusão de questões de relance para manter o foco ou aprofundar informações e reflexões. Os usuários dos serviços foram contatados quando do acompanhamento nos CAPS ou durante internações em hospitais da rede, tendo como critérios de inclusão ter, no mínimo, 18 anos de idade e estar fora de crise e em condições de par- ticipar da entrevista, o que era avaliado por profissional do campo que o convidava a participar da pesquisa.

Realizaram-se as entrevistas em dois hospitais psiquiátricos de Belo Horizonte, Minas Gerais, e em dois serviços ambulatoriais de saúde mental, sendo um situado em Betim, Minas Gerais, e outro na cidade de Carmo, Rio de Janeiro, Brasil, serviços esses onde havia maior facilidade de acesso dos pesquisadores.

A seleção dos participantes, dentre todos os que atendiam aos critérios de inclusão, ocorreu de forma aleatória e de acordo com a aceitação em participar da pesquisa. Não houve definição do número de participantes a priori, sendo que o critério para suspensão da coleta de novas entrevistas foi o de saturação dos dados. Entrevistaram-se 39 pessoas com questões acerca da vivência da sexualidade, dentre as quais o que pensam por saúde sexual. As entrevistas foram gravadas e realizadas em salas privativas nos serviços de saúde mental.

Asseguraram-se aos sujeitos o sigilo e o anonimato das informações, bem como o direito de se negar a participar da pesquisa ou interromper sua participação a qualquer momento, sem qualquer prejuízo. Todos os participantes assinaram o Termo de Consentimento Livre e Esclarecido, não havendo recusa entre os sujeitos convidados, exceção a uma jovem que não aceitou o registro por meio do gravador digital.

Os dados foram tratados pelo método da análise estrutural de narraçãa ${ }^{11}$ que seguiu os seguintes passos: transcrição fiel dos relatos gravados em áudio, leitura vertical, análise horizontal, nomeação das sequências e primeira categorização, busca das representações por densidade na estrutura do discurso, análise transversal com elaboração de um esquema das representações e análise aprofundada dos resultados, cotejando-os com os de outros autores sobre as representações encontradas.

O Comitê de Ética em Pesquisa da Universidade Federal de Minas Gerais aprovou o estudo focado nas representações dos profissionais da saúde, e os serviços de saúde participantes, o Comitê de Ética em Pesquisa da Universidade Federal de Minas Gerais (COEP/UFMG), e pela Comissão Nacional de Ética em Pesquisa (CONEP), atendendo às exigências das Resoluções de $n^{\circ}$. 196/96 e 25/97, do Conselho Nacional de Saúde, aprovaram a coleta de dados com pessoas com transtornos mentais. 


\section{Resultados e discussão}

\section{As representações sobre saúde sexual de pessoas com transtornos mentais: contexto social dos participantes}

Participaram deste estudo 22 homens e 17 mulheres com transtornos mentais, com idades entre 18 e 72 anos, sendo que vinte se encontravam internados e 19 em acompanhamento em serviços substitutivos. Em relação aos diagnósticos psiquiátricos, $80 \%$ têm psicoses graves e $20 \%$ retardo, demências e epilepsias. Vinte e dois pacientes têm algum tipo de renda e os demais são dependentes de caridade alheia. Dezoito estudaram, no máximo, por quatro anos, e dez, por oito anos. Dez são analfabetos. Um tem Ensino Médio completo e um é graduado. Em sua maioria, os entrevistados moram acompanhados. Três já foram moradores de rua.

Vinte entrevistados têm filhos, mas seis não mantêm contato com eles. Todos os entrevistados afirmaram quase não ter amigos e viverem em desamparo familiar. Entre as mulheres, quatorze tiveram relacionamento estável, mas somente três viviam com o companheiro no momento da entrevista. Oito homens já tiveram companhei$\mathrm{ra}(\mathrm{o})$, mas somente dois disseram manter um relacionamento conjugal estável. Atribuiu-se a instabilidade dos relacionamentos a situações de agressividade, infidelidade do parceiro(a), uso de drogas e álcool, e 25\% dos entrevistados afirmaram usar drogas ilícitas e 30\%, álcool; comportamento que foi justificado como uma forma de aliviar as dificuldades que encontram no dia a dia e também pelo contexto de vida.

Em todas as falas, observou-se baixa autoestima e sentimento de inferioridade relacionado ao preconceito social, pelo fato de terem um transtorno mental. Os dados apresentados caracterizam contexto social de dificuldades sociais e econômicas importantes.

\section{O tabu em torno da sexualidade das pessoas com transtornos mentais}

Os entrevistados conversam pouco sobre a temática da sexualidade, o que evidencia que ela permanece um tabu:

Tenho alguns amigos em quem confio, mas não falo de sexo com eles (E1, homem, 23 anos).

As dificuldades em falar sobre sexualidade mostraram-se decorrentes do fato de essa temática ser vista como pertencente à esfera do íntimo, do privado, do secreto:
Eu não gosto de falar de intimidade, não. Conversar sobre minha vida particular eu não gosto, porque a vida é só da gente [...] (E35, homem, 35 anos); É difícil falar disso (E14, mulher, 22 anos).

O silenciamento, em torno da temática, decorre do fato de a sexualidade ser vista como algo proibido, clandestino, que deve se dar somente entre quatro paredes e de forma confidencial ${ }^{12}$. A sexualidade mostrou-se também um assunto sobre o qual não se conversa com os parceiros, inclusive os casados:

Como que a gente pode falar de sexo, a mulher da gente vai pensar o quê? (E7 homem, 52 anos).

Em se tratando de casais, essas dificuldades se dão pelo medo de o entrevistado se expor e jogar por terra imagens que ele acredita que o outro tem dele, e pelo temor quanto às consequências que essas falas podem trazer para a relação ${ }^{13}$. As dificuldades mostraram-se ainda maiores em situações em que a sexualidade foi vivida de forma violenta:

Ah, eu não gosto de falar disso (referindo-se a sua vida sexual) porque eu fui estuprada (E4, mulher, 30 anos). Eu tenho vergonha, o sexo era obrigado pelos outros (E39, homem, 51 anos).

Relembrar essas experiências parece trazer à tona o sofrimento vivido, o que se tenta evitar.

Referências de conversas com outras pessoas sobre sexualidade foram poucas, e, nestas, os sujeitos afirmaram fazê-las com amigos do mesmo sexo. O tabu está em falar de sexualidade de forma franca, sobre si mesmo e escutar o interlocutor falar de si, sobretudo quando este é do sexo oposto. Além disso, nenhum entrevistado relatou ter conversado sobre o assunto com profissionais de saúde.

O ocultamento em torno da temática foi identificado em estudos realizados com outros grupos e foi apontado por estes autores como um aspecto dificultador não só para a prevenção dos agravos sexualmente transmissíveis, mas também para a vivência de uma sexualidade prazerosa ${ }^{14,15}$, como também observado neste estudo. Dentre as cinco mulheres e dois homens que relataram violência sexual sofrida, somente dois confessaram a situação à outra pessoa, mas afirmaram que não foram escutados nem amparados:

Eu contei para minha mãe, mas ela disse que eu era mentirosa e 'louca' (E4, mulher, 30 anos); Naquela época, não tinha essa opção de fazer denúncia (E16, mulher, 38 anos). Duas das mulheres violentadas tiveram como agentes infratores o próprio pai.

Entre os homens, a violência sexual sofrida foi por outros homens, tendo havido ainda uma 
situação em que a violência sexual sofrida não foi relatada na entrevista, mas constava no prontuário do paciente. Esses homens afirmaram não ter denunciado a violência sofrida, o que se acredita decorrer da vergonha em fazê-lo. Em um desses casos, a violência sexual sofrida manteve-se por anos dentro da Instituição de saúde mental, sem que nada fosse feito. Tratava-se de um paciente com maiores dificuldades cognitivas e de comunicação, e, por isso, não conseguia se defender.

No entanto, alguns não reconhecem como violência o fato de ter relações sexuais sem que a razão seja o desejo. Alguns entrevistados afirmaram, por exemplo, fazer sexo somente para garantir algum dinheiro para a sobrevivência ou para comprar drogas:

Eu transava na rua para comprar drogas (E14, mulher, 22 anos).

Houve um homem (E3, 50 anos) que relatou ter feito sexo com outro homem para comprar gás de cozinha. Tais decisões extrapolam, obviamente, a objetividade do fato e devem ser refletidas no conjunto da situação do sujeito. Mas, há que se ressaltar que a violência sexual pode ocasionar diversos tipos de danos às vítimas, situação que pode permanecer durante toda a vida, ocasionando problemas de saúde física, reprodutiva, mental, fobias, pânico, síndrome do estresse pós-traumático, depressão e outras alterações psicológicas, com repercussões na sua vida social e familiar, com diminuição da autoestima, comprometimento dos estudos, emprego, separações conjugais, abandono de casa, gestação, além da contração de DST e HIV/AIDS ${ }^{14}$. Em alguns relatos, verificaram-se estes impactos, como se apresenta a seguir:

Não gosto de sexo. Nunca senti prazer (nas vivências sexuais). Acho que é por causa do estupro (E4, mulher, 30 anos).

\section{As dificuldades do autocuidado para a saúde sexual de pessoas com transtornos mentais}

Nenhum entrevistado apresentou representações sobre saúde sexual como um direito. O despreparo para desfrutar a sexualidade de forma sadia, prazerosa e respeitosa foi marcante, assim como a preferência por não ter relações sexuais pelo temor de adquirirem uma DST ou gravidez não desejada, o que, ao lado de vivências de gravidez não planejada, evidenciam o desconhecimento no uso de métodos preventivos.

A maioria dos entrevistados já tinha ouvido falar sobre as DST, mas não sabiam falar nada a respeito:
Já ouvi falar, mas não sei o que é (E28, homem, 63 anos); Acho que pega no beijo (E24, mulher, 68 anos).

No entanto, essas pessoas reconhecem as possibilidades da transmissão de agravos pela via sexual. A aids é a mais temida dentre as DST, o que decorre de sua representação como 'destruidora e mortal'. Somente uma minoria disse ter recebido informações sobre as DST nos serviços de saúde mental.

O preservativo masculino é conhecido pela maioria; mas muitas mulheres disseram só saber que existe sem nunca terem manuseado ou feito uso de um com o parceiro. Houve um participante que afirmou vender o preservativo que ganha no serviço de saúde para comprar leite, considerando ser um desperdício fazer uso com sua parceira:

Ela é de confiança (E29, 42 anos).

A confiança em parceiras, aparentemente sadias e conhecidas, mostrou-se ser o maior entrave ao uso do preservativo, pelos homens. As mulheres, por sua vez, não conseguem exigir o uso pelos parceiros e não conhecem o preservativo feminino:

Meu marido não aceita usar camisinha (E16, 38 anos).

Por dificuldades em se manter e de sustentar os filhos, as mulheres acabam cedendo ao sexo desprotegido; além disso, não foi raro ouvir relatos de relações sexuais sem vontade, apenas para satisfazer seus parceiros, afirmando ser um dever da mulher, evidenciando a influência dos estereótipos de gênero nas formas de viver a sexualidade ${ }^{4}$.

Mesmo nos casos em que os entrevistados tinham percepção mais acurada da necessidade de se autocuidar, o que decorreu de experiências de DST contraídas, ou de pessoas próximas que as contraíram, o uso de preservativo não foi mantido, justificado pela diminuição do prazer:

É ruim. Não consigo resistir à tentação de transar sem camisinha porque é muito melhor (E2, homem, 27 anos).

Esse relato evidencia a valorização do prazer como superior à saúde. A norma social da obrigatoriedade de sexo seguro para se prevenir das DST não é, portanto, uma representação, assimilada por todos. Houve, ainda, relatos de abandono do uso regular, alegando-se que o preservativo estoura, o que leva a indícios de inabilidade pelo não aprendizado, pelo aprendizado incorreto ou falta de destreza, mas que pode encobrir a falta de vontade de se prevenir.

$\mathrm{Na}$ maioria dos relatos, há desmotivação e falta de sentido para o autocuidado, em consequência do desamparo social e familiar: 
Ninguém tá nem aí pra mim, pra que me cuidar? (E17, mulher, 47 anos).

Em geral, os participantes, quando interrogados, manifestaram interesse em aprender sobre as DST e HIV/AIDS, e em ter esclarecimentos sobre a sexualidade, considerando o assunto relevante e necessário. $\mathrm{O}$ autocuidado para a prevenção das DST e HIV/AIDS mostrou-se, portanto, realizado de forma limitada e ineficaz, estando prejudicado por aspectos que incluem o tabu, envolvendo a sexualidade; o pouco conhecimento sobre as DST e métodos preventivos; a confiança exagerada nos parceiros ou medo de perdê-los; a hierarquia entre os gêneros e a ausência de integralidade nas ações e serviços de saúde, o que também foi encontrado em estudos que analisam dados de outros grupos populacionais ${ }^{15-17}$. A especificidade do grupo de pessoas com transtornos mentais é seu contexto social, marcado por pobreza, ignorância, abandono, preconceito e drogadição. Além de dificultar o autocuidado, esse contexto apresentou-se favorecedor de situações de maior vulnerabilidade, como a de venda de sexo e violência sexual.

\section{As representações dos profissionais de saúde acerca da sexualidade de pessoas com transtornos mentais}

A análise realizada dos grupos focais permitiu detectar que houve homogeneidade nas falas dos profissionais, não sendo possível concluir que algum tipo de representação esteja relacionado, exclusivamente, a um grupo profissional em decorrência de sua formação. Tal achado permite afirmar que formações acadêmicas diferentes e níveis diferentes de escolaridade entre os participantes não influenciaram nas representações encontradas nos relatos analisados.

Vale lembrar que, para a pesquisa, não houve observação da prática profissional dos profissionais de saúde. Buscou-se, aqui, ouvir suas representações naquilo que se dispuseram relatar. É o olhar de cada um sobre sua prática e como se vê nela, sem que isso seja exatamente o que acontece no cotidiano.

\section{Medo do outro, medo da sexualidade do 'outro'}

Nas discussões dos grupos focais dos profissionais, emergiram representações de negação da sexualidade das pessoas com transtorno mental. Dessa forma, o profissional mantém-se afastado por não reconhecer a sexualidade dessas pessoas como natural; mas como diferente, negando-a e censurando-a. A representação central é a de que sexualidade de pessoas com transtorno mental é algo anormal, que traz medo e repulsa:

Você tem que ficar de cima porque a sexualidade deles é aflorada demais; A questão da sexualidade na saúde mental é um grupo de pessoas um pouco diferente dos outros pacientes em si.

Predominam representações de hipersexualidade e busca intensa pelo ato sexual ${ }^{18,19}$, o que define as maneiras como os profissionais cuidam dessas pessoas.

As posturas desses profissionais revelam-se, portanto, afastamento e proibição das manifestações e práticas sexuais pelos usuários assistidos:

A gente tenta controlar a questão assim, de que não tenha ato dentro do serviço e até a fantasia deles; Tenta sempre ter profissional na convivência, próximo, pra estar evitando esse tipo de conversa (sobre sexo). A gente orienta. Até questão assim, fora, a gente tenta evitar esse tipo de comportamento; Um dia eu falei assim: vocês estão dando beijo aqui dentro? Não pode.

A defesa da proibição de manifestações entre os usuários aparece como a forma mais segura de se lidar com a sexualidade de pessoas com transtornos mentais, temendo a própria incapacidade de refletir sobre sexualidade e agir de forma adequada:

Nós chegamos a conversar entre nós (os profissionais), e ai a gente achou melhor que não tivesse (possiveis atividades relacionadas à expressão da sexualidade entre os pacientes), porque senão todo mundo ia querer. Ia ser uma confusão danada.

O silenciamento, em torno da temática da sexualidade e de suas diferentes formas de expressão, revela representações dos profissionais de saúde mental sobre sexualidade como ato sexual, algo proibido ou clandestino, que deve se dar somente "entre quatro paredes". Assim, a sexualidade é da esfera da vida privada, não devendo fazer parte de interferência de outras pessoas ou ser objeto de cuidado e assistência de forma integral, mas de especialista. Este é, também, o ponto de vista das pessoas com transtornos mentais. Tais representações parecem residir na associação da sexualidade com aspectos considerados imorais, apontando estereótipos sociais preconceituosos, com acentuado viés moralista:

O que a gente percebe é que os pacientes com transtorno mental, muitos quando estão em surto, apresentam aumento do quadro sexual. Não ligam se tem companheiro ou não, a promiscuidade é grande, a gente vê alguns casos que não respeitam essa questão." 
Os profissionais expuseram situações cotidianas, nos serviços de saúde mental, que desvelam representações sobre a sexualidade dos usuários e reforçam a ideia de que é 'algo humano, mas diferente dos outros humanos':

E tem uma sedução, você percebe, dependendo do momento do serviço. Se eles estão com menos roupa, tem aquele... É da vida, é humano. Obviamente que a gente a percebe maior em alguns casos, um instinto exacerbado. A questão do uso, do abuso em função do uso, da necessidade da troca do corpo, que é o que eles têm. Sexo, para eles, é sem pensar em nada.

Esses profissionais parecem se defender daquilo com o qual não conseguem lidar, pois, ao invés de abordarem a problemática da sexualidade, optam, muitas vezes, por negligenciar a demanda apresentada pela pessoa por eles assistida:

A gente faz de conta que não vê, mas essas manifestações da sexualidade, elas surgem de diversas formas. Desde paciente tendo relação com outro paciente dentro do CAPS; desde um paciente fazendo um balão com o preservativo.

As representações, entre os profissionais de saúde, sobre o sexo, o ato sexual e o prazer de pessoas com transtornos mentais foram de vergonha, de proibição e de desajuste. São representações muito antigas que persistem na cultura sexual atual, também entre toda a população ${ }^{18,19}$, na qual estão incluídas as próprias pessoas com transtornos mentais, como se evidenciou no presente estudo.

Desta forma, a negação da existência da sexualidade ou de 'instinto exacerbado', além da sexualidade concentrada no ato sexual, são representações dos profissionais de saúde mental, que contribuem para o distanciamento, silenciamento e a perpetuação de estigmas e preconceitos sobre a vivência plena da sexualidade de pessoas com transtornos mentais.

\section{Considerações finais}

Esta pesquisa permitiu desvelar que pessoas com transtornos mentais não representam saúde sexual como direito e encontram dificuldades para se cuidar em face de violência sexual e de infecções sexualmente transmissíveis, tanto pelo contexto de exclusão e pobreza, quanto por influências de estereótipos de gênero difundidos na sociedade. A pesquisa ainda mostrou que os profissionais que atuam nos serviços de saúde mental possuem representações de negação da expressão da sexualidade das pessoas com transtorno mental. No entanto, acreditam que esses modos de gestão da vida sexual são correntes e provenientes da "própria loucura", devendo, de modo geral, serem reprimidos e sobre os quais se prefere o silêncio e o distanciamento. Além disso, a quase inexistência de ações de prevenção de DST e HIV/AIDS junto às pessoas com transtornos mentais compromete a vivência de uma sexualidade sadia e segura para elas.

Os resultados apontam a necessidade de capacitações para os profissionais, com novas abordagens, considerando os direitos humanos e a integralidade como princípios do cuidado em saúde mental. Eles evidenciam a necessidade de se considerar os aspectos psicossociais e o contexto material de existência dessa população nas ações educativas para que sejam efetivas. Sugerese, assim, o desenvolvimento de rodas de conversas entre os profissionais, para que haja troca e explicitação de dúvidas que propiciem rupturas de estereótipos traduzidos em preconceitos e até mesmo em atitudes incorretas que prejudicam o cuidado à pessoa com transtorno mental.

\section{Colaboradores}

JAG Barbosa e MCMR Souza participaram da coleta, análise e interpretação dos dados; redação e revisão do artigo; MIF Freitas participou da concepção do projeto; coleta, análise e interpretação final dos dados; redação do artigo e revisão crítica relevante do conteúdo intelectual; e aprovação final da versão publicada.

\section{Agradecimentos}

Ao financiamento do Ministério da Saúde, da Unesco, da CAPES e da Fapemig. 


\section{Referências}

1. Guimarães MDC, Campos LN, Melo APS, Carmo RA, Machado CJ, Acurcio FA. Prevalence of HI, syphilis, hepatitis $\mathrm{B}$ and $\mathrm{C}$ among adults with mental illness: a multicenter study in Brazil]. Rev Bras Psiquiatr 2009; 31(1):43-47.

2. Guimarães MDC, Mckinnon K, Campos LN, Melo APS, Wainberg M. HIV risk behavior of psychiatric patients with mental illness: a sample of Brazilian patients. Rev. Bras. Psiquiatr 2010; 32(4):349-360.

3. Brito PF, Oliveira CC. A sexualidade negada do doente mental: percepções da sexualidade do portador de doença mental por profissionais de saúde. Ciência $e$ cognição 2009; 14(1):246-254.

4. Gagnon J. Uma interpretação do desejo: ensaios sobre o estudo da sexualidade. Rio de Janeiro: Ed. Garamound; 2003.

5. Paiva V, Pupo LR, Barboza R. O direito à prevenção e os desafios da redução da vulnerabilidade ao HIV no Brasil. Rev Saude Publica 2006; 40(Supl):S109-119.

6. Wainberg ML, González MA, Mckinnon K, Elkington DP, Mann CG, Mattos PE. Targeted ethnography as a critical step to inform cultural adaptations of HIV prevention interventions for adults with severe mental illness. Soc Sci Med 2007; 65(2):296-308.

7. Pinto DS, Mann CG, Wainber M, Mattos P, Oliveira, SB. Sexuality, vulnerability to HIV, and mental health: an ethnographic study of psychiatric institutions. Cad Saude Publica 2007; 23(9):2224-2233.

8. Giami A. Representações e sexualidade: psicologia social e pluridisciplinaridade. In: Loyola MA, organizador. A sexualidade nas Ciências Humanas. Rio de Janeiro: EDUERJ; 1998. p. 201-225.

9. Moscovici S. Representações sociais: investigações em psicologia social. 6a ed. Petrópolis: Vozes; 2009.

10. Giami A, Veil C. Enfermeiras frente à AIDS: representações, condutas, permanência e mudanças. Canoas: Ed. ULBRA; 1997.

11. Demazière D, Dubar C. Analyser les entretiens biographiques. L'exemple de récits dïnsertions. Paris: Nathan; 1997. (Coll. Essais \& Recherches).
12. Paiva V, Pupo LR, Barboza R. O direito à prevenção e os desafios da redução da vulnerabilidade ao HIV no Brasil. Rev Saude Publica 2006; 40(Supl.):109-119.

13. Kauffmann J. La trame conjugale, analyse du couple par son linge. Paris: Nathan; 1992.

14. Lambrocini LM, Fegadoli D, Correa MEC. Significado da violência sexual na manifestação da corporeidade: um estudo fenomenológico. Rev. Esc. Enferm. USP 2010; 44(2):401-406.

15. Oltramari LC. Representações sociais da aids, relações conjugais e confiança [tese]. Florianópolis: Universidade Federal de Santa Catarina; 2007.

16. Santos CO, Iriart JAB. Significados e práticas associados ao risco de contrair HIV nos roteiros sexuais de mulheres de um bairro popular de Salvador, BA. Cad Saude Publica 2007; 23(12):2896-2905.

17. Aboim S. Risco e prevenção do HIV/Aids.: uma perspectiva biográfica sobre os comportamentos sexuais em Portugal. Cien Saude Colet 2012; 17(1):99-112.

18. Miranda FAN, Furegato ARF. Percepções da sexualidade do doente mental pelo enfermeiro. Rev Latino-am Enfermagem 2002; 10(2):207-213.

19. Gomes AMT, Oliveira DC, Santos EI, Espírito Santo CC, Valois BRG, Pontes APM . As facetas do convívio com o HIV: formas de relações sociais e representações sociais da AIDS para pessoas soropositivas hospitalizadas. Esc Anna Nery 2012; 16(1):111-120.

Artigo apresentado em 16/03/14

Aprovado em 06/11/14

Versão final apresentada em 08/11/14 